\title{
Juvenile Xanthogranuloma in a Pediatric Patient with Langerhans Cell Histiocytosis
}

\author{
Radha Ram ${ }^{\mathrm{a}, \mathrm{b}}$ Marissa D. Marolfa Patricia Chévez-Barrios ${ }^{\mathrm{a}, \mathrm{c}}$ \\ Honey H. Herce ${ }^{a, b}$ \\ ${ }^{a}$ Department of Ophthalmology, Baylor College of Medicine, ${ }^{b}$ Department of Ophthalmology, Texas Children's \\ Hospital, and 'Departments of Pathology and Genomic Medicine and Ophthalmology, Houston Methodist Hospital, \\ Houston, TX, USA
}

\section{Established Facts}

- Juvenile xanthogranuloma can present as single or multiple papules, typically in young children with a median age of 2 years.

- Definitive diagnosis of juvenile xanthogranuloma requires histopathologic evaluation.

\section{Novel Insights}

- Juvenile xanthogranuloma can mimic Langerhans cell histiocytosis.

- To our knowledge, this is the first published case of a pediatric patient with a new diagnosis of juvenile xanthogranuloma greater than 5 years following Langerhans cell histiocytosis and systemic therapy.

\section{Keywords}

Langerhans cell histiocytosis · Juvenile xanthogranuloma · Eyelid mass · Pediatric ophthalmology · Eyelid

\footnotetext{
Abstract

Purpose: To report a case of juvenile xanthogranuloma that simulated a chalazion and to discuss the association between juvenile xanthogranuloma and Langerhans cell histiocytosis. Method: Case report and review of literature. $\boldsymbol{R e}$ sults: A 13-year-old boy with a prior history of Langerhans cell histiocytosis was referred to our clinic for a possible cha-
}

lazion. The patient had undergone treatment for Langerhans cell histiocytosis 10 years prior. The patient underwent an excisional biopsy. Histopathology revealed a proliferation of histiocytes and lymphocytes with Touton giant cells, consistent with a diagnosis of juvenile xanthogranuloma. Conclusions: Though the relationship between Langerhans cell histiocytosis and juvenile xanthogranuloma has yet to be fully elucidated, juvenile xanthogranuloma should be included in the differential diagnosis for any former Langerhans cell histiocytosis patient presenting with a new cutaneous lesion.

(c) 2017 S. Karger AG, Basel

\section{KARGER}

E-Mail karger@karger.com

www.karger.com/oop
(C) 2017 S. Karger AG, Basel Honey H. Herce, MD

Department of Ophthalmology, Baylor College of Medicine

Texas Children's Hospital, 6701 Fannin, Ste 610.25

Houston, TX 77030 (USA)

E-Mail honey.herce@bcm.edu 
Table 1. Cytological and immunohistochemical features of Langerhans cell histiocytosis, juvenile xanthogranuloma, and our patient

\begin{tabular}{|c|c|c|c|}
\hline & Langerhans cell histiocytosis & Juvenile xanthogranuloma & Our patient \\
\hline Cytology & $\begin{array}{l}\text { Touton-like multinucleated giant } \\
\text { cells are demonstrated rarely. } \\
\text { The main lesional cell is the } \\
\text { Langerhans cell histiocytosis cell } \\
\text { accompanied by pronounced } \\
\text { inflammatory infiltrates. }\end{array}$ & $\begin{array}{l}\text { Classic Touton giant cells are } \\
\text { demonstrated in most cases. } \\
\text { The main lesional cells are } \\
\text { mononuclear cells and } \\
\text { multinucleated cells with } \\
\text { sparse inflammatory } \\
\text { infiltrates. }\end{array}$ & $\begin{array}{l}\text { Mononuclear cells } \\
\text { and Touton giant } \\
\text { cells were } \\
\text { demonstrated. }\end{array}$ \\
\hline $\begin{array}{l}\text { Immuno- } \\
\text { histochemistry }\end{array}$ & $\begin{array}{l}\text { CD1a + } \\
\text { S100 + } \\
\text { CD207 (langerin) + } \\
\text { CD68 usually - }\end{array}$ & $\begin{array}{l}\text { CD1a - } \\
\text { S100 - } \\
\text { CD207 (langerin) - } \\
\text { CD68 + }\end{array}$ & $\begin{array}{l}\text { CD1a - } \\
\text { S100 - } \\
\text { CD207 (langerin) - } \\
\text { CD68 + }\end{array}$ \\
\hline
\end{tabular}

\section{Introduction}

Langerhans cell histiocytosis (LCH) and non-LCH are separate disease entities that rarely develop in the same patient. $\mathrm{LCH}$ is an uncommon disease with a variable prognosis; the prognosis largely depends on the patient's age and the presence of multifocality and/or dissemination, which may be life-threatening. Juvenile xanthogranuloma (JXG), a non-LCH, is usually a benign and selflimiting disease; however, childhood presentations of JXG with ocular and orbital involvement may lead to glaucoma and blindness. In the majority of cases, JXG is an isolated diagnosis in an otherwise healthy patient. We describe a patient with a diagnosis of JXG several years after being diagnosed and treated for LCH.

\section{Case Report}

A 13-year-old boy with a past medical history of LCH was referred to the pediatric ophthalmology department by his pediatrician for evaluation of a possible right upper eyelid chalazion. The patient's mother noticed the lesion on his right upper eyelid 3 weeks prior to presentation and noted that it had progressively enlarged since onset. There had been one episode of bleeding from the lesion after the patient had manually squeezed the lesion. The patient denied eye redness, lid ptosis, additional lesions, visual changes, ocular misalignment, or other eye problems. He denied recent fevers and weight loss. Other than occasional asthma flares, he had been in good health.

Ten years prior to presentation to our clinic, the patient had been diagnosed with $\mathrm{LCH}$ of the left gingiva and mandible, for which he had completed 12 months of vinblastine and prednisone therapy. He had been to regular follow-ups with the oncology department with no history of disease recurrence.

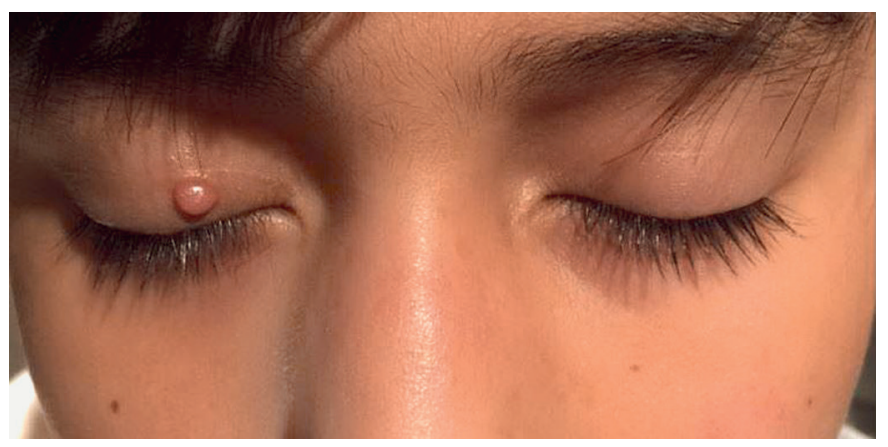

Fig. 1. Color photograph of the patient's eyelids at presentation.

Ocular examination revealed a raised, nonmobile, pink, pearly, nodular lesion without umbilication on the anterior skin of the right upper eyelid (Fig. 1). Uncorrected visual acuity measured $20 / 20$ bilaterally. The patient had normal motility, normal pupils, and no orbital proptosis. Anterior segment exam and fundus exam were normal. He did not have other skin lesions nor lymphadenopathy.

The differential diagnosis for an eyelid lesion in this particular patient included chalazion, molluscum contagiosum, pyogenic granuloma, JXG, and recurrence of LCH.

The patient underwent an excisional biopsy. Histopathology showed a dermal proliferation of mononuclear cells and rare Touton giant cells with admixed eosinophils and lymphocytes. The histiocytes were positive with CD68 and negative with CD1a, S100, and CD207. CD5 and CD3 were positive in the infiltrating lymphocytes, consistent with a diagnosis of JXG (Fig. 2; Table 1).

Given the benign nature of JXG, no further treatment was necessary in this particular patient. Clinical examination 1 month later revealed no evidence of residual tumor or recurrence. The patient continues to follow up with the oncology department for his $\mathrm{LCH}$. 
Fig. 2. Histopathologic findings of the skin nodule supportive of the diagnosis of juvenile xanthogranuloma. a Low-power view of the skin lesion with lesion in the dermis composed mostly of histiocytes and some lymphocytes (hematoxylin and eosin, $4 \times$ magnification). b High magnification showing histiocytes, small lymphocytes, and Touton giant multinucleated cells (arrows, hematoxylin and eosin, 40× magnification). c CD68 is positive in multinucleated and histiocytes cells. d S100 shows the multinucleated giant cells being negative. CD207 (langerin) (e) and CD1a (f) are negative in lesional histiocytes and multinucleated cells and positive in normal antigenpresenting dendritic cells of the epidermis (immunohistochemistry with DAB chromogen and hematoxylin counterstain, $20 \times$ magnification).
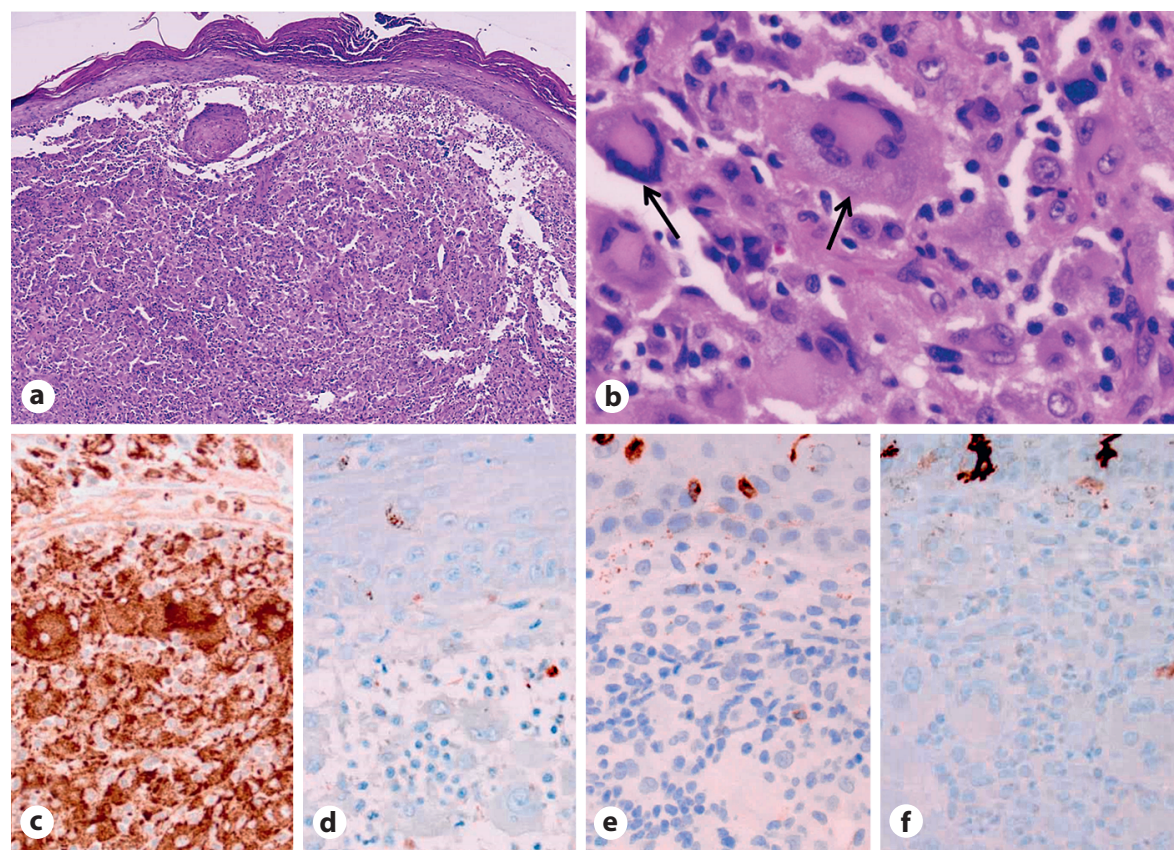

\section{Discussion}

The patient's medical history and appearance of the lesion heightened the level of suspicion for a possible histiocytic disorder. Both JXG and LCH can yield cutaneous lesions with similar appearances. Histopathologic evaluation is necessary to distinguish the two entities [1].

LCH and JXG are the two most frequently encountered histiocytic disorders observed in the pediatric population [2]. Histiocytic disorders are characterized by proliferation of dendritic cells or macrophages [3]. They are generally classified into two major categories based on histopathology: $\mathrm{LCH}$ and non-LCH. JXG is considered a non-LCH lesion [4].

$\mathrm{LCH}$ is a proliferative disorder of CD1a+/CD207+ myeloid dendritic cells which appear morphologically similar yet genetically distinct from Langerhans cells of the skin [5]. LCH affects children with a frequency of 3-5 cases per million children annually [2]. Bone and skin are among the most commonly affected [5]. Skin findings range from pigmented papular lesions to an eczematous rash. Though the incidence of orbital involvement in patients with LCH was historically seen as uncommon [6], some have reported incidence rates as high as 37.5\% [7]. Ramzan et al. [8] discussed 5 cases of exclusive eyelid involvement of LCH, 2 of whom were children. Systemic chemotherapy depends on the organs involved [5]. All patients with $\mathrm{LCH}$ are at risk for relapse, highlighting the importance of long-term follow-up [2].

As a non-LCH disorder, the dendritic cell type involved in JXG lacks CD1a, CD207, and S100, the markers associated with LCH [9]. JXG typically presents as a benign nodular skin lesion and rarely involves deep tissues and organs [1]. Ocular JXG is the most common extracutaneous manifestation, estimated to occur in $0.3 \%$ of cases $[9,10]$. Uveal tract lesions represent the most common form of ocular JXG [3]. A recent retrospective case series examining 30 patients with ocular and ocular adnexal JXG found that JXG affected the iris in $68 \%$ of patients, the conjunctiva in $19 \%$ of patients, the eyelid in $6 \%$ of patients, the choroid in $6 \%$ of patients, and the orbit in $3 \%$ of patients [11]. Cutaneous JXG typically regresses spontaneously; however, ocular JXG may require treatment to avoid possible complications [3].

This case was challenging at the time of intraoperative diagnosis because of the history of $\mathrm{LCH}$; thus, immunohistochemistry studies were essential to exclude a cutaneous recurrence of $\mathrm{LCH}$ and introduced the new diagnosis of JXG in this patient. This case describes the emergence of JXG years after systemic therapy for LCH. This association is not well understood but has been noted in a number of case reports and case series. Patrizi et al. [12] reported 2 cases of JXG presenting during chemotherapy for LCH; 1 of the 2 cases involved the eyelid. Strehl et al. 
[10] reported 8 cases in which patients were diagnosed with JXG 3 months to 5 years following diagnosis and therapy for $\mathrm{LCH}$, with a mean of 2.4 years following diagnosis and therapy for LCH; 4 of the 8 cases involved the eyelid, and the JXG lesions occurred between 1.5 years to 5 years after therapy for $\mathrm{LCH}$.

Transformation of LCH into JXG through an unknown mechanism mediated by chemotherapy has been suggested. There have also been rare reports of coexisting LCH and JXG in patients who had not yet undergone treatment, suggesting a biologic connection between the two entities $[13,14]$. It has also been suggested that $\mathrm{LCH}$ triggers the formation of JXG through an immune-mediated reaction [10]. To our knowledge, there are no reported cases of $\mathrm{LCH}$ developing in a patient with known JXG.

To the best of our knowledge, there have been no reported cases of JXG occurring more than 5 years after diagnosis and treatment for $\mathrm{LCH}$. Though the relation- ship between LCH and JXG has yet to be fully elucidated, JXG should be included in the differential diagnosis for any former $\mathrm{LCH}$ patient presenting with a new cutaneous or ocular lesion, regardless of the patient's age and time span from the initial diagnosis of LCH.

\section{Statement of Ethics}

The subject provided consent to publication of this case and its associated images. No IRB approval was required for publication of this case report.

\section{Disclosure Statement}

The authors report no conflicts of interest, including financial interests, activities, relationships, and affiliations. The manuscript was not previously presented at a meeting nor previously published.

\section{References}

1 Weitzman S, Egeler RM: MyiLibrary. Histiocytic Disorders of Children and Adults. Cambridge, New York, Cambridge University Press, 2005.

2 McClain KL: Clinical manifestations, pathologic features, and diagnosis of Langerhans cell histiocytosis. In: Post TW (ed): UpToDate. Waltham, MA.

3 Hoyt CS, Taylor D: Pediatric Ophthalmology and Strabismus. 4th ed. New York, London, Elsevier Saunders, 2013.

4 Vaiselbuh SR, Bryceson YT, Allen CE, Whitlock JA, Abla O: Updates on histiocytic disorders. Pediatr Blood Cancer 2014;61:13291335.

5 Monsereenusorn C, Rodriguez-Galindo C: Clinical Characteristics and Treatment of Langerhans Cell Histiocytosis. Hematol Oncol Clin North Am 2015;29:853-873.
6 Mokal NJ, Shetty KP, Arora R, Thatte MR: Langerhans cell histiocytosis: orbital involvement as an unusual location. Plast Reconstr Surg 2001;107:813-817.

7 Vosoghi H, Rodriguez-Galindo C, Wilson MW: Orbital involvement in Langerhans cell histiocytosis. Ophthal Plast Reconstr Surg 2009;25:430-433.

8 Ramzan M, Yadav SP, Bhalla S, Jamwal P, Grover AK, Sachdeva A: Eyelid nodule: a rare presentation of Langerhans cell histiocytosis. J Pediatr Hematol Oncol 2012;34:e158-e160.

9 Puttgen KB: Juvenile xanthogranuloma. In: Post TW (ed): UpToDate. Waltham, MA.

10 Strehl JD, Stachel K, Hartmann A, Agaimy A: Juvenile xanthogranuloma developing after treatment of Langerhans cell histiocytosis: case report and literature review. Int J Clin Exp Pathol 2012;5:720-725.
11 Samara WA, Khoo CT, Say EA, Saktanasate J, Eagle RC Jr, Shields JA, Shields CL: Juvenile xanthogranuloma involving the eye and ocular adnexa: tumor control, visual outcomes, and globe salvage in 30 patients. Ophthalmology 2015;122:2130-2138.

12 Patrizi A, Neri I, Bianchi F, Guerrini V, Misciali C, Paone G, Burnelli R: Langerhans cell histiocytosis and juvenile xanthogranuloma. Two case reports. Dermatology 2004; 209:57-61.

13 Yu H: A child with coexistent juvenile xanthogranuloma and Langerhans cell histiocytosis. J Am Acad Dermatol 2010;62:329-332.

14 Tran DT, Wolgamot GM, Olerud J, Hurst S, Argenyi Z: An "eruptive" variant of juvenile xanthogranuloma associated with Langerhans cell histiocytosis. J Cutan Pathol 2008; 35:50-54 